\title{
ALFABETIZAÇÃO CIENTÍFICA COM ENFOQUE CTSA: PRODUÇÃO DE UM JORNAL DA CIÊNCIA NO ENSINO MÉDIO PÚBLICO
}

\author{
Joelma Goldner Krüger ${ }^{1}$, Ana Carolina Miranda Prezilius², \\ Sidnei Quezada Meireles Leite ${ }^{3}$
}

\author{
Secretaria de Estado de Educação do Espírito Santo \\ Av. César Hilal, 1111 - Santa Lúcia - CEP: 29056-085 - Vitória - Espírito Santo. \\ Programa de Pós-graduação em Educação em Ciências e Matemática \\ Instituto Federal do Espírito Santo - Campus Vitória \\ Avenida Vitória, 1729 - Jucutuquara, Vitória, Espírito Santo.
}

\begin{abstract}
RESUMO
O projeto escolar "Jornal da Ciência" foi uma atividade de pesquisa/extensão interdisciplinar extracurricular de caráter educativo e cultural. 0 objetivo deste trabalho foi estudar o processo de construção do jornal da ciência, na escola pública de ensino médio do Estado do Espírito Santo, promovendo debates e reflexões sobre as questões relativas à ciência, além de se constituir um espaço de aprendizagem para os alunos de iniciação científica do projeto escolar. Vale citar que as discussões epistemológicas travadas neste trabalho foram realizadas à luz da pedagogia de projetos escolar. A equipe do projeto é constituída por cinco alunos de iniciação científica júnior do ensino médio, uma aluna de iniciação científica de licenciatura em química, professores de ciências e pesquisadores. Cada número do JEC é composto por um editorial, uma pesquisa desenvolvida no Espírito Santo, uma pesquisa em nível de Brasil/Mundo, um personagem da história da ciência e um acontecimento local.
\end{abstract}

Palavras-chave: projeto escolar, jornal escolar, ensino de ciências, pensamento crítico.

\begin{abstract}
The Project Work "Official School of Science" is a research activity / interdisciplinary extension extracurricular educational and cultural character. The objective of this work was to study the process of building the science journal, school, public high schools in the state of Espirito Santo, promoting discussion and reflection on issues relating to science, and constitute a learning space for students undergraduate research project at school. It is worth mentioning that the epistemological discussions waged in this work were carried out in light of the Labor Education Project. The project team consists of five undergraduate students of junior high school, a student of scientific initiation degree in chemistry, science teachers and researchers. Each edition of the JEC is comprised of an editorial, a research developed in the Holy Spirit, a research level of Brazil / World, a character in the history of science and a local event.
\end{abstract}

Keywords: school project, school journal, science teaching, critical thinking.

\footnotetext{
1 professora de Química, Mestre em Educação em Ciências e Matemática. Secretaria de Estado de Educação do Espírito Santo. E-mail: joelmagoldner@gmail.com

2 aluna de iniciação científica do curso de licenciatura em Química do Instituto Federal do Espírito Santo - Campus Vila Velha. E-mail: carolmiranda0211@hotmail.com

${ }^{3}$ professor de Educação em Ciências e Química, D.Sc. Programa de Pós-graduação em Educação em Ciências e Matemática. Instituto Federal do Espírito Santo - Campus Vitória. E-mail: sidneiquezada@gmail.com
}

Revista Eletrônica Debates em Educação Científica e Tecnológica, ISSN: 2236-2150 - V. 03, N. 02, p. 79 - 97, Dezembro, 2013 


\section{INTRODUÇÃo}

O relatório da Unesco (2003), intitulado "A ciência para o século XXI: uma nova visão e uma base de ação", apontou, entre outras coisas, para a necessidade de desenvolver o pensamento crítico em alunos da educação básica como sendo importante para o mundo contemporâneo, sobretudo, para o desenvolvimento de um pensamento voltado para paz mundial. Também, apontou para iniciativas na educação científica que pudessem contribuir com a eliminação dos preconceitos no que diz respeito as diversidades e conscientizar a população sobre o papel da ciência. Para isso, ressaltou o documento a necessidade de introdução nas escolas de metodologias de ensino inovadoras. Em outro documento, o relatório da Organização para a Cooperação e Desenvolvimento Econômico (OCDE, 2006), também aponta para a necessidade de renovação das práticas pedagógicas realizadas na educação em ciências e matemática. De certa forma, parece haver uma convergência no que diz respeito à educação CTS/CTSA discutida por Santos e Auler (2011). Vale citar que estas demandas da educação mundial, sobretudo, da educação científica, também foram debatidas por Aikenhead (2009).

Segundo Sasseron e Carvalho (2008), na literatura nacional encontra-se tanto a expressão "Letramento Científico" (e.g. MAMEDE e ZIMMERMANN, 2007, SANTOS e MORTIMER, 2001), como também o tempo "Alfabetização Científica" (e.g. AULER e DELIZOICOV, 2001, LORENZETTI e DELIZOICOV, 2001, CHASSOT, 2000). Já os pesquisadores de língua espanhola utilizam a expressão "Alfabetización Científica” (e.g. GIL-PÉREZ e VILCHES-PEÑA, 2001); nas publicações em língua inglesa aparece o termo "Scientific Literacy" (e.g. LAUGKSCH, 2000, Bybee, 1995); e, nas publicações francesas, encontramos o uso da expressão "Alphabétisation Scientifique" (e.g. FOUREZ, 2000). Já autores portugueses tem usado o termo "Literacia Cientítica" (e.g. TENREIRO-VIEIRA e VIEIRA, 2013). Nós utilizamos a expressão "Alfabetização Científica" baseadas na ideia de alfabetização concebida por Paulo Freire. Para o pensador, "a alfabetização é mais que o simples domínio psicológico e mecânico de técnicas de escrever e de ler. É o domínio destas técnicas em termos conscientes". Neste caso, a alfabetização deve possibilitar ao analfabeto a capacidade de organizar seu pensamento de maneira lógica, além de auxiliar na construção de uma consciência mais crítica em relação ao mundo que o cerca.

Nogueira (2005) discorre da origem da palavra projeto, que é do latim projectu, lançando para diante. A princípio, um projeto só começa a ter uma estrutura a partir da realização de ações 
e articulações. É fundamental re(pensar) os projetos dentro de uma perspectiva mais ampla, surgindo desta forma o projeto escolar, no qual o objetivo é ampliar a visão em função de uma prática. No caso deste trabalho, procuramos enfocar a o "projeto escolar" por meio do Jornal da Ciência.

\begin{abstract}
Autonomia nos projetos no sentido de poder decidir sua própria trajetória, seu próprio caminhar e optar pela sua própria tecedura de significados em sua rede [...] as flexibilizações pedagógicas imbricadas na pratica do trabalho com projetos permitem o posicionamento, às ações, às escolhas, às oportunidades, às trajetórias, etc., as quais são situações propensas à tomada de decisões, o que não poderá correr sem a prática da livre escolha, ou seja, da autonomia (NOGUEIRA, 2005, p. 47).
\end{abstract}

O projeto escolar é uma forma pedagógica de organizar os conhecimentos escolares, no qual pode ser influenciado pelo conhecimento globalizado. A articulação dos conhecimentos escolares, de certa forma, é uma maneira de estabelecer a atividade de ensino e aprendizagem, tendo o cuidado de considerar que tais conhecimentos não se prescrevem para sua compreensão de uma forma rigorosa, nem em função de determinadas referências disciplinares já estabelecidas (HERNÁNDEZ e VENTURA, 2007).

A organização dos Projetos de trabalho se baseia fundamentalmente numa concepção da globalização entendida como um processo muito mais interno do que externo, no qual as relações entre conteúdos e áreas de conhecimento têm lugar em função das necessidades que traz consigo o fato de resolver uma série de problemas que subjazem na aprendizagem. Esta seria a idéia fundamental dos Projetos. A aprendizagem (HERNÁNDEZ e VENTURA, 2007, p. 63).

O objetivo deste trabalho foi estudar os aspectos pedagógicos do projeto escolar Jornal da Ciência, realizado numa escola pública de ensino médio do Estado do Espírito Santo, à luz do pensamento crítico e da alfabetização científica.

\title{
2. PERCURSO METODOLÓGICO
}

\section{A) 0 Estudo}

A pesquisa foi desenvolvida nos moldes de um estudo de caso, de natureza qualitativa e de caráter exploratório, conforme Marcone e Lakatos (2009). Procuramos apresentar uma 
reflexão e análise a cerca do projeto escolar promovida no processo de construção de jornal escolar da ciência. 0 desenvolvimento do projeto escolar teve a realização de reuniões de equipes com os professores de ciências, seleção dos alunos de iniciação científica mediadas por prova e entrevistas e realização de oficinas formativas de jornal da ciência.

\section{B) Local da Pesquisa}

A presente investigação foi realizada na Escola Estadual de Ensino Fundamental e Médio (EEEFM) Marinete de Souza Lira, situada na Rua Vitória Régia, S/N, Bairro Feu Rosa, Município de Serra, Espírito Santo.

\section{C) Sujeitos}

Os sujeitos dessa pesquisa foram os alunos de IC Jr do ensino médio, a aluna monitora de IC e os professores colaboradores e coordenadores do projeto "Jornal Escolar da Ciência" da área de ciências. Para garantir a integridade dos sujeitos envolvidos, resolvemos preservar a identidade, não sendo divulgada nenhuma informação que possibilite a identificação dos mesmos. As informações fornecidas serão utilizadas somente para realização da pesquisa.

\section{D) Coleta e Análise dos Dados}

Os dados coletados com base em observações, análise de documentos oficiais, leituras de artigos e livros da área de Ensino de Ciências e Matemática e aplicação de entrevistas coletivas com os sujeitos envolvidos para levantamento das percepções. Foram analisadas as percepções dos alunos de IC ao longo das reuniões de equipe, buscando identificar indícios da pedagogia por Projeto de Trabalho. Essas categorias foram escolhidas para dar clareza na organização e análise dos conteúdos tendo como referência principal, Bardin (2004).

\section{0 CONTEXTO DA PESQUISA}

A Fundação de Amparo à Pesquisa do Estado do Espírito Santo, em 2011, criou o Programa Estadual de Iniciação Científica Júnior com apoio do CNPq. Este programa é uma política pública que visa, entre outros objetivos, aproximar as instituições de pesquisa das escolas públicas do estado do Espírito Santo e promover mudanças nas práticas pedagógicas realizadas na sala de aula da educação básica pública, especialmente as situadas em regiões à margem da sociedade. Cada projeto financiado apresenta um pequeno recurso de 
equipamento e custeio, bolsas de iniciação científica para alunos do ensino médio e bolsa de iniciação científica para alunos de cursos de graduação.

O Jornal Escolar da Ciência é um projeto de parceria entre o Instituto Federal do Espírito Santo (IFES) - Campus Vitória e a EEEFM Marinete de Souza Lira, onde se busca reunir alunos do Ensino Médio com seus professores e pesquisadores do IFES, para debater questões relacionadas à alfabetização científica a partir da divulgação periodicamente do Jornal Escolar da Ciência. O projeto está sendo desenvolvido numa escola de um bairro carente, da região metropolitana da Grande Vitória, no estado do Espírito Santo. O Jornal da Ciência foi uma atividade interdisciplinar extracurricular de caráter cultural e educativo, composto por um editorial, uma pesquisa desenvolvida no Espírito Santo, uma pesquisa em nível de Brasil/Mundo, um personagem da história da ciência e um acontecimento local.

Jornal é um meio de comunicação impresso, geralmente um produto derivado do conjunto de atividades denominado jornalismo. As características principais de um jornal são: o uso de "papel de imprensa" - mais barato e de menor qualidade que os utilizados por outros materiais impressos; a linguagem própria - dentro daquilo que se entende por linguagem jornalística; e é um meio de comunicação de massas - um bem cultural que é consumido pelas massas. Os jornais têm conteúdo genérico, pois publicam notícias e opiniões que abrangem os mais diversos interesses sociais. No entanto, há também jornais com conteúdo especializado em economia, negócios ou desporto, entre outros. A periodicidade mais comum dos jornais é a diária, mas existem também aqueles com periodicidade semanal, quinzenal e mensal. No caso da presente proposta, busca-se criar um Jornal da Ciência na Escola com periodicidade mensal. Para Bonini (2011), a prática do jornal escolar vem ao encontro das propostas dos Parâmetros Curriculares Nacionais, promovendo a conexão de saberes e melhoria do processo de ensino-aprendizagem da língua portuguesa no contexto brasileiro.

\section{O PROJETO ESCOLA JORNAL ESCOLAR DA CIÊNCIA}

O desenvolvimento do projeto Jornal da Ciência teve três etapas. Vale citar que este trabalho se debruçou a analisar a etapa I deste projeto de extensão (Quadro 1). Cabe ressaltar que na Etapa I foi constituído um grupo de trabalho formado por cinco alunos de Ensino Médio 
(bolsistas de Iniciação Científica Júnior), professores das mais diversas áreas, um aluno de iniciação científica da Licenciatura em Química e pesquisadores.

Quadro 1. Etapas do Projeto Jornal Escolar da Ciência.

Etapa I: Treinamento/Formação: Consistiu no período de atividades dos bolsistas no qual estão envolvidos com reuniões, oficinas de orientação e palestras sobre o tema abordado, além de realização do estudo dirigido e treinamento da metodologia.

Etapa II: Desenvolvimento: Etapa de desenvolvimento do projeto escolar "Jornal da Ciência na Escola" que deverá prever atividades de levantamento e sistematização de dados, construção de gráficos e figuras, interpretação de resultados, elaboração de conclusões.

Etapa III: Participação de um seminário de Avaliação dos Projetos.

Na primeira Oficina de Contextualização do Jornal, houve uma pequena atividade de integração do grupo e foi feita uma apresentação geral do projeto de extensão. Na tentativa de demonstrar as possibilidades do jornal escolar, alguns temas foram debatidos tais como o vazamento de água de uma rede local do bairro, a dengue, a obtenção de água potável, a importância de um museu da cultura e da ciência, a importância do Instituto de Pesquisa da Economia para o Estado do Espírito Santo, a agropecuária no Estado do Espírito Santo, entre outros. Para nortear as discussões, foram utilizados jornais de circulação regional e nacional como fonte de pesquisa. Alguns alunos deram seu depoimento a cerca da importância desse projeto em suas vidas, destacando-se a oportunidade de se aprender mais sobre a ciência e novas culturas, visando fomentar opiniões futuras. Como forma de marketing, os bolsistas sugeriram uma comunicação de curiosidades em forma de manchete, para chamar atenção dos potenciais leitores.

Na Etapa II acontece o desenvolvimento do jornal propriamente dito, quando o respectivo responsável por cada coluna constrói o seu texto e há o processo de melhoramento por meio das reuniões com o monitor e a equipe de professores. A Etapa III acontece à apresentação de um pôster em um Seminário de Avaliação dos Projetos de PIBIC Jr, promovidos pela FAPES.

Com a constituição da equipe de trabalho, foi possível estabelecer uma organização para o jornal escolar, cujos temas tratados foram: (a) editorial, "um fato na ciência no Espírito Santo", 
"um fato na ciência no Brasil ou no mundo", "um fato na história da ciência” e "aconteceu!". Esse grupo de trabalho é coordenado por professor da área de ciências com apoio dos gestores da escola. Mensalmente, um editorial é um texto de apresentação do jornal da ciência construído por um dos integrantes.

A coluna da "Ciência no Espírito Santo" é construída por meio de uma prévia investigação de um grupo de pesquisa de umas das instituições de pesquisa do estado do Espírito Santo. Esse processo de busca é enriquecedor porque promove descobertas e uma ampliação da visão de mundo. Os alunos podem lançar mão de uma entrevista e de fotografias, quando é possível e viável.

As Colunas da "Ciência no Brasil/América Latina/Mundo" e "História da Ciência" são construídas por meio de uma pesquisa na internet a partir de algum tema identificado nos jornais ou revistas de divulgação científica. Já a Coluna “Aconteceu”, está é construída com base em algum acontecimento local ou regional com implicações socioambientais. Nesse caso, busca-se levantar os fatos daquele mês por meio de entrevistas e reportagens realizadas no jornal local e da TV. Por sua vez cabe ressaltar que o ponto de partida para a definição de um Projeto de Trabalho é a escolha do tema. Segundo Hernández e Ventura (2007) o tema do Projeto de Trabalho pode: ser a partir de uma experiência; ser um fato da atualidade; um problema e; pertencer ao currículo oficial. Logo, o Jornal Escolar da Ciência tem cinco colunas (Quadro 2), com os mais diversos temas, na proposta do Projeto de Trabalho.

Quadro 2. Descrições das cinco colunas do Jornal Escolar da Ciência.

\begin{tabular}{|c|c|c|c|c|}
\hline \multicolumn{5}{|l|}{ 1a Edição: Geral } \\
\hline \multicolumn{5}{|l|}{ Coluna } \\
\hline Editorial & A Ciência no Mundo & $\begin{array}{l}\text { A Ciência no } \\
\text { Espírito Santo }\end{array}$ & $\begin{array}{l}\text { Aconteceu/ } \\
\text { Acontecerá }\end{array}$ & História da Ciência \\
\hline $\begin{array}{l}\text { Chamada para } \\
\text { despertar o } \\
\text { interesse pela } \\
\text { leitura do jornal } \\
\text { com os principais } \\
\text { aspectos de cada } \\
\text { coluna }\end{array}$ & $\begin{array}{l}\text { Construída por meio } \\
\text { de uma pesquisa na } \\
\text { internet e livros a } \\
\text { partir de algum tema } \\
\text { identificado nos } \\
\text { jornais ou revistas de } \\
\text { divulgação científica }\end{array}$ & $\begin{array}{l}\text { Construída por } \\
\text { meio de uma prévia } \\
\text { investigação de um } \\
\text { grupo de pesquisa } \\
\text { de umas das } \\
\text { instituições de } \\
\text { pesquisa do estado } \\
\text { do Espírito Santo }\end{array}$ & $\begin{array}{l}\text { Construída com } \\
\text { base em algum } \\
\text { acontecimento } \\
\text { local ou regional } \\
\text { com implicações } \\
\text { socioambientais }\end{array}$ & $\begin{array}{l}\text { Construída por meio } \\
\text { de uma pesquisa na } \\
\text { internet e livros a } \\
\text { partir de algum tema } \\
\text { identificado nos } \\
\text { jornais ou revistas de } \\
\text { divulgação científica }\end{array}$ \\
\hline
\end{tabular}

Fonte: Dados da pesquisa.

Durante a Oficina de Produção do Jornal percebemos que os alunos se motivaram com os temas apresentados. Discutirmos a percepção dos alunos a partir de fotografias, a partir de 
imagens e pequenos textos. Também foram discutidas algumas questões com base na forma do jornal. Finalmente, foram aplicadas algumas dinâmicas com base em temas préestabelecidos: a obtenção da água potável, as pesquisas realizadas pelo Incaper e a realização do Rio+20. Os alunos receberam pequenos textos sobre esses assuntos e tiveram que produzir um pequeno resumo.

O objetivo destas dinâmicas foi desenvolver opinião crítica sobre os temas apresentados. Logo, um dos empregos do Projeto de Trabalho é beneficiar a elaboração de estratégias de organização dos conhecimentos escolares, dentre eles: a relação entre os distintos conteúdos em torno de problemas e; o tratamento da informação (HERNÁNDEZ; VENTURA, 2007). Por sua vez, Projeto de Trabalho tem este propósito: em relacionar os conteúdos curriculares das disciplinas do ensino médio com o Jornal Escolar. Abaixo, segue uma discussão feita durante o minicurso. Iniciaram-se os questionamentos (Quadro 3) com a seguinte pergunta motivadora aos alunos: 0 que é ciência?

Quadro 3. Trechos das falas apresentadas durante o minicurso diante do questionamento: 0 que é ciência?

Coordenador: 0 que é ciência?

Alunos: Tudo o que estuda a nossa vida. 0 cotidiano!

Aluna A: A busca pelas respostas, a filosofia.

Aluna I: Estudo de todas as coisas.

Coordenador: Será que a ciência é igual à de antes?

Aluna I: As coisas mudaram.

Coordenador: Estudo sobre determinado assunto!

Alunos: Sim.

Coordenador: Então é a busca pela compreensão dos fatos da vida?

Alunos: Sim!

Aluna J: A busca pela compreensão de coisas incompreensíveis.

Aluna J: Ciência é tudo!

Fonte: Dados da pesquisa.

Percebe-se na fala da aluna J "A busca pela compreensão de coisas incompreensíveis”, no qual ela mesma chega à seguinte conclusão “Ciência é tudo!”. A aluna está correta! O Jornal Escolar contemplará todas as ciências, ou seja, todas as grandes áreas de estudo, segundo o Conselho Nacional de Desenvolvimento Científico e Tecnológico (CNPq). Depois solicitou aos alunos bolsistas para pensarem na concepção do jornal (o que vai tratar/como vai ser construído) e depois a forma, o tipo do jornal. Foram apresentadas as áreas escolhidas de um estudo 
realizado pelos professores do curso de CTS (Ciência, Tecnologia e Sociedade) da rede pública do Estado do Espírito Santo, e por fim sendo sugerido a utilização desses temas como norteadores para o Jornal Escolar. Os temas são: Agricultura; Água Potável; Biocombustível; Saúde e Alimentação; Energia; Vícios, Violência e Valorização Da Vida; Lixo; Mármore e Granito; e Petróleo; e Biotecnologia e Transgênicos. Na figura 1 está apresentado um momento de construção do jornal na escola pública.

Figura 1. Pesquisa, no laboratório de informática da escola pública estadual, dia 25 de outubro de 2012, para a edição de novembro do Jornal Escolar da Ciência.

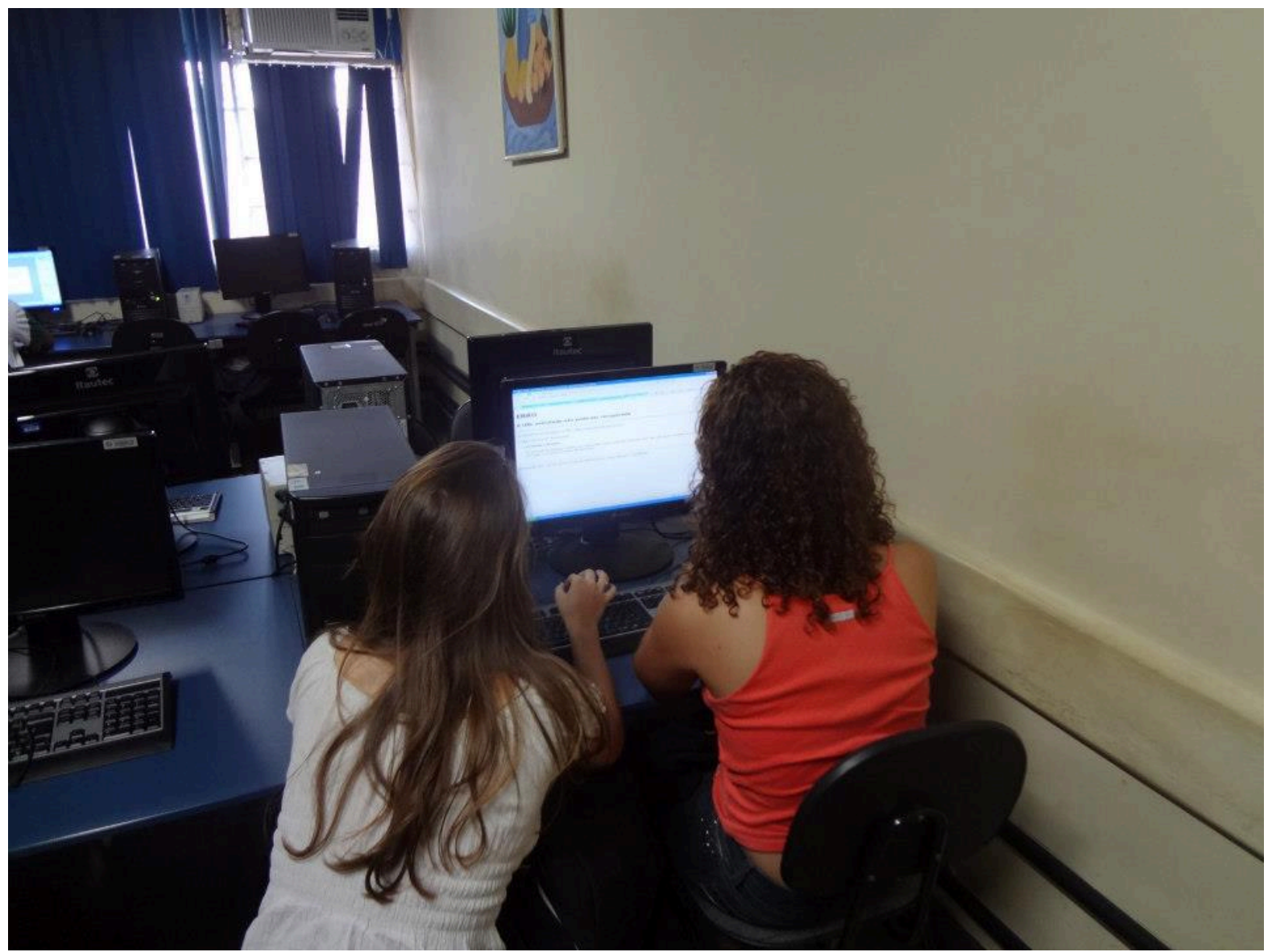

Fonte: Dados da pesquisa.

Por tratar de assuntos relacionados ao desenvolvimento do Estado do Espírito Santo, acredita-se que esse trabalho possa servir como catalisador para a definição do futuro dos jovens, buscando indicar possíveis caminhos a serem percorridos na sua vida pessoal e profissional. Talvez, ao desenvolver esse projeto, a escola passe a se localizar na rota do conhecimento científico nas várias áreas do conhecimento, levando ao jovem a sonhar com um bom curso técnico em uma boa escola ou com sua formação acadêmica em nível de 
graduação em uma Universidade/Instituto. Os temas tratados no Jornal Escolar servirão como geradores de discussão em sala de aula, propiciando a racionalização e a apropriação dos conteúdos de forma lúdica e significativa para alunos e professores. Já em na outra parte da Oficina de Produção de Jornal a monitora do Projeto abarcou com os alunos bolsistas sobre a redação de um Jornal, no qual ela destacou as seguintes partes: origem do Jornal Escolar; vantagens do Jornal Escolar; objetivos; tipos de Jornais que podem ser utilizados no projeto; redação; matérias; diagramação; e material visual.

Formamos alunos para que desenvolvam as diferentes habilidades e competências necessárias para que possam se inserir no meio e integrar-se ao convívio social, no qual encontrarão, dentre tantas alternativas, também o mercado de trabalho, o qual tem se apresentado cada vez mais competitivo. [...] Se nossa missão é formar o cidadão integral, parece coerente que também olhemos para as exigências das habilidades e competências que este segmento tem cobrado dos cidadãos e nos moldemos, planejando diferentes estratégicas educacionais, para auxiliar nesse processo de formação (NOGUEIRA, 2005, p. 14).

Durantes as reuniões contempladas na Etapa I (Treinamento/Formação) também houve, por meio do coordenador geral, oficinas para o desenvolvimento da percepção dos alunos e da capacidade de relatar algum fato de uma forma simples e atraente para os futuros leitores do Jornal Escolar. Além disso, começou-se a desenhar, juntamente com os alunos, o formato do Jornal Escolar, encerrando desta forma a Etapa I do projeto de extensão, além do desenvolvimento da autonomia dos alunos no Projeto de Trabalho.

A autonomia que tende a propiciar o livre pensar e agir poderá desenvolver no aluno a capacidade de, no futuro, continuar aprendendo, buscando soluções, desenvolvendo novos conhecimentos, independentemente de ter um tutor demonstrando os passos e os caminhos de um processo (NOGUEIRA, 2005, p. 47).

Na Figura 2 está apresentado a parte da frente do Jornal Escolar da Ciência produzido pelos alunos do ensino médio para o mês setembro de 2012. Nesta edição, por exemplo, foram abordados os temas sobre blocos econômicos mundiais, participação do Estado do Espírito Santo no desenvolvimento do Brasil, um breve histórico sobre os ciclos econômicos 


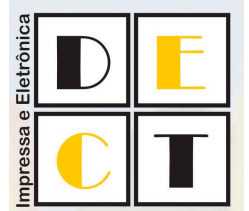

brasileiros, um breve histórico sobre a construção da ferrovia Madeira Mamoré, e a construção de Brasília.

Figura 2. A parte da frente do Jornal Escolar da Ciência produzido pelos alunos do projeto escolar para o mês setembro de 2012 .

\section{JORNAL ESCOLAR DA CIÊNCIA}

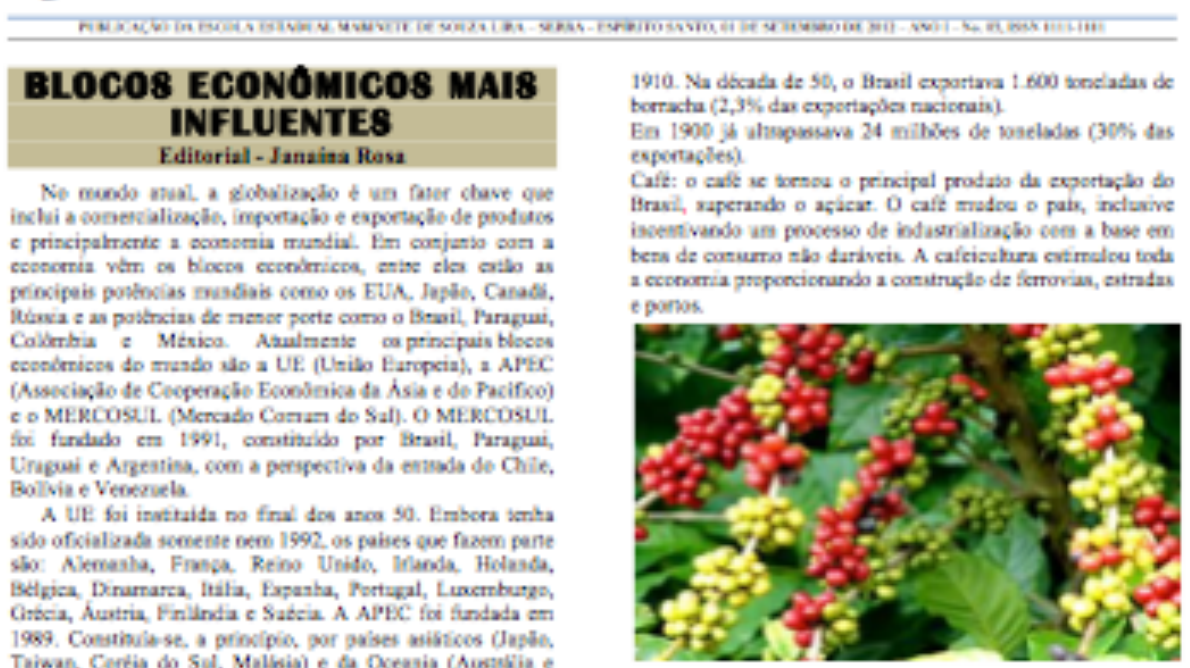

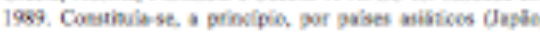

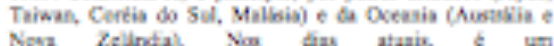

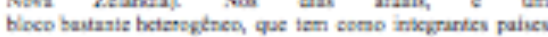

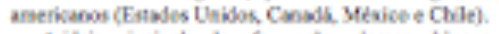

A idciaprincipal de forragbo desues bieces it a

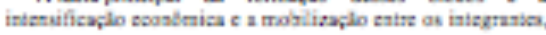

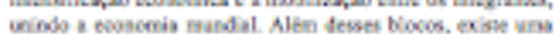

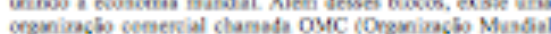
do Cornetriah, que integra bados os pabes que participan do

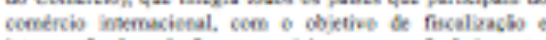

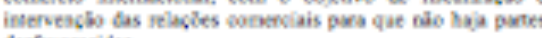
desfonoresidas

\section{CICLOS ECONOMICOS BRABILEIRO}

\section{Cikacia no Munde - Katty Mosteire}

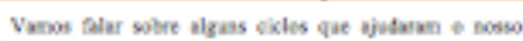
puis.

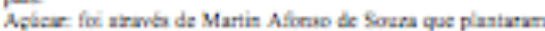

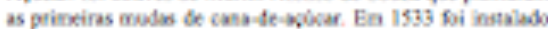

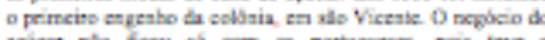
acieat nibo fecou wo com on partagueuse, pora teve

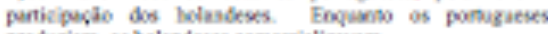
poodiziam, os Melasdeies ceeserializaram

Oaroc o geverno pertapuks beacava navas banie de riquera no qual reviponos o ant po socho de encortrat curo no liravit. Mas fei seesene no fial do sto. XVII que os buoderaness

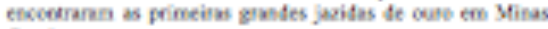
Gersis.

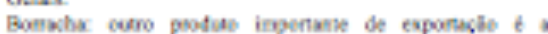

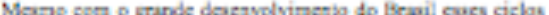
aisda abo matro importarken, pois ajedaran virios estadas do nosso pais a crescer e ser oque theje.

\section{PARTICIPACÃO DO E.S. NO DESENVOLVIMENTO BRASILEIRO \\ Clécia ano Espirito Sante - Andreia Amaral}

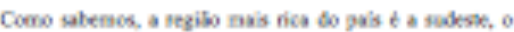

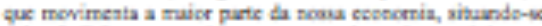

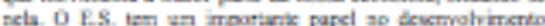

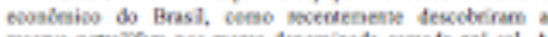
reserve jecolikn aos nives decowinade cameta ped sal. A prodeplo expichaha, em mbta, $b$ de 600 batrix por da e por extpa, 60. Con was resebernas a pazanentes das nayalies

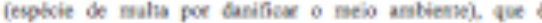

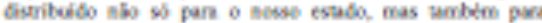
cutros estades braikitos. Vice rasalar cue cumrto maiar for

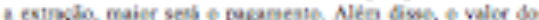

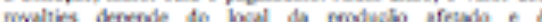

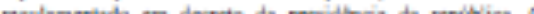

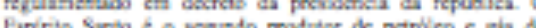
Bras? perdeoda aperes para o Fio de laecil

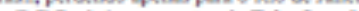

O E.S. viriza os portos de Tubuso e 60 Vilnia, que esta

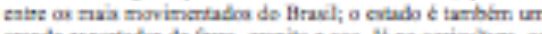
grande exportador de ferro, gratio e apa. Ai ra agriculina, ai

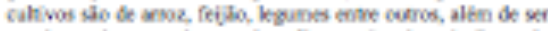

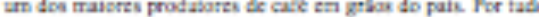

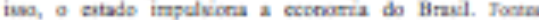

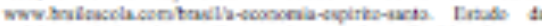

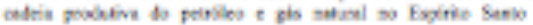

\section{FADES H:-}

Fonte: Dados da pesquisa. 


\section{ALFABETIZAÇÃo CIENTÍFICA}

No processo de escrita de cada coluna do jornal escolar, o aluno perpassava por atividades complementares, no processo de construção do seu texto, por meio de pesquisas em livros e sites, leituras de jornais e revistas de grande circulação, da leitura de notícias locais e regionais, além da contribuição de pessoas de notório saber. Para Ijuim (2005) o jornal escolar é um processo, que pode envolver várias pessoas, favorecendo o desenvolvimento da humanização dos envolvidos. Desta forma, os alunos tiveram o envolvimento com outras pessoas na busca de informações, ratificando que não se aprende apenas na escola, com o ensino formal, pois aprender é um processo dialogado, comunicativo, sendo importante a informação, a contribuição, que os outros trazem, no processo educativo e de humanização, beneficiando a autonomia, sobretudo, é o diálogo promovido para estabelecer as inferências, que auxilia a dar sentido à forma de ensino e de aprendizagem que se anseia com os Projetos (HERNÁNDEZ e VENTURA, 2008).

Por fim elaborou-se uma quadro (1) contemplando um resumo dos temas tratados em cada mês, de maio a dezembro de 2012, com suas respectivas colunas, como uma forma de ilustrar os diversos temas abordados mensalmente relacionados ao movimento CTSA, na busca pela promoção da alfabetização científica dos alunos de iniciação científica júnior. Dessa forma, foi dada a oportunidade dos alunos exercerem a autonomia, o espírito crítico, apesar de todas as falhas que podem acontecer em um projeto, mas a chance da oportunidade que eles tiveram de participar do projeto mudou, de certa forma, ajudou no seu crescimento.

A autonomia surge, em primeira instância - no projeto, quando ocorre a argumentação sobre o tema, posteriormente no momento do planejamento das ações, em que o aluno pode e deve dizer o que quer fazer, como vai fazer, para que vai fazer, quando vai fazer e com quem vai fazer. Após planejado o projeto, muitas outras situações vão surgir durante as demais fases, que exigirão dos alunos novos posicionamentos e novas tomadas de decisões, fatores que continuam durante todo o projeto, auxiliando no desenvolvimento do sujeito autônomo (NOGUEIRA, 2009, p. 48). 
Quadro 1. Edições do jornal escolar da ciência e o assunto de suas respectivas colunas.

\begin{tabular}{|c|c|c|c|c|c|}
\hline \multirow{2}{*}{$\begin{array}{l}\text { EDIÇÃO } \\
\text { TEMA }\end{array}$} & \multicolumn{5}{|c|}{ COLUNA } \\
\hline & Editorial & $\begin{array}{l}\text { A Ciência no } \\
\text { Mundo }\end{array}$ & $\begin{array}{c}\text { A Ciência no Espírito } \\
\text { Santo }\end{array}$ & $\begin{array}{l}\text { Aconteceu/ } \\
\text { Acontecerá }\end{array}$ & História da Ciência \\
\hline $\begin{array}{l}\text { 1) Maio/ } \\
\text { Geral }\end{array}$ & $\begin{array}{l}\text { Chamada com os } \\
\text { principais } \\
\text { aspectos de cada } \\
\text { coluna }\end{array}$ & $\begin{array}{c}\text { Água Potável: } \\
\text { Quanto custa e como } \\
\text { obtemos? }\end{array}$ & $\begin{array}{c}\text { Programa de } \\
\text { Desenvolvimento Rural } \\
\text { Sustentável: Uma } \\
\text { experiência do INCAPER }\end{array}$ & Rio+ 20 vem aí! & $\begin{array}{l}\text { Você sabe quem foi } \\
\text { Heinrich Rudolf } \\
\text { Hertz (1857-1894)? }\end{array}$ \\
\hline $\begin{array}{l}\text { 2) Junho/ } \\
\text { Saúde e } \\
\text { Alimentação }\end{array}$ & $\begin{array}{l}\text { Alimentos } \\
\text { transgênicos }\end{array}$ & $\begin{array}{l}\text { Propriedades dos } \\
\text { Alimentos }\end{array}$ & Fertilizantes na Agricultura & $\begin{array}{l}\text { Alimentação } \\
\text { Escolar }\end{array}$ & $\begin{array}{l}\text { Conservação dos } \\
\text { Alimentos }\end{array}$ \\
\hline $\begin{array}{l}\text { 3) Julho/ } \\
\text { Água }\end{array}$ & Chuva Ácida & Enchentes & Enchentes em Vila Velha & $\begin{array}{c}\text { Desabamentos em } \\
\text { Guarapari }\end{array}$ & $\begin{array}{c}\text { Doenças } \\
\text { Transmitidas pela } \\
\text { Água }\end{array}$ \\
\hline $\begin{array}{l}\text { 4) Agosto/ } \\
\text { Energia }\end{array}$ & $\begin{array}{l}\text { Racionamen-to de } \\
\text { energia }\end{array}$ & $\begin{array}{c}\text { Energia Renovável } \\
\text { no Brasil }\end{array}$ & $\begin{array}{l}\text { Usinas Hidrelétricas no } \\
\text { Espírito Santo }\end{array}$ & $\begin{array}{l}\text { Usina Hidrelétrica } \\
\text { de Belo Monte }\end{array}$ & Fontes de Energia \\
\hline $\begin{array}{l}\text { 5) Setembro/ } \\
\text { Economia }\end{array}$ & $\begin{array}{c}\text { Blocos } \\
\text { Econômicos mais } \\
\text { Influentes } \\
\end{array}$ & $\begin{array}{c}\text { Ciclos Econômicos } \\
\text { Brasileiros }\end{array}$ & $\begin{array}{c}\text { Participação do Espírito } \\
\text { Santo no Desenvolvimento } \\
\text { Brasileiro }\end{array}$ & $\begin{array}{l}\text { Estrada de Ferro } \\
\text { Madeira Mamoré }\end{array}$ & $\begin{array}{l}\text { Construção de } \\
\text { Brasília }\end{array}$ \\
\hline $\begin{array}{l}\text { 6) Outubro/ } \\
\text { Olimpíadas }\end{array}$ & $\begin{array}{l}\text { História dos Jogos } \\
\text { Olímpicos }\end{array}$ & $\begin{array}{c}\text { Balanço das } \\
\text { Olimpíadas } 2012\end{array}$ & Heróis Capixabas & $\begin{array}{l}\text { Jogos Olímpicos } \\
\text { Rio } 2016\end{array}$ & $\begin{array}{c}\text { Seleção Brasileira de } \\
\text { Futebol }\end{array}$ \\
\hline $\begin{array}{l}\text { 7)Novembro/ } \\
\text { Política }\end{array}$ & Mensalão & $\begin{array}{l}\text { Política e Vida de } \\
\text { Barack Obama }\end{array}$ & Greve na Ufes 2012 & $\begin{array}{c}\text { Movimentos } \\
\text { Populares no } \\
\text { Brasil } \\
\end{array}$ & $\begin{array}{l}\text { Voto Feminino no } \\
\text { Brasil }\end{array}$ \\
\hline
\end{tabular}

Somente em alguns meses, o editorial teve o papel de apresentação do jornal (Figura 1). 0 restante dos meses, a partir das discussões realizadas durante as reuniões de trabalho, ficou decidido que o Editorial seria uma espécie de mini matéria (Figura 2). Vale citar que durante as reuniões de trabalho sempre se fazia a escolha do tema do jornal, o que orientava a pesquisa, a escrita das colunas, a construção dos textos, a correção e reescrita dos textos, quando necessário. Esse processo era dialético, o que fazia com que os alunos participante do jornal produzisse reflexões, com idas e vindas, sobre o processo de construção da edição do mês.

Se pensarmos os projetos temáticos ou de trabalhos como uma dinâmica que propicia a autonomia dos alunos, que permita que ele planeje suas ações, atos, procedimentos, etc., então provavelmente os projetos podem ser uma das possibilidades de flexibilizar nossas ações pedagógicas [...] essa autonomia que tende a propiciar o livre pensar e agir poderá desenvolver no aluno a capacidade de, no futuro, continuar aprendendo, buscando soluções, desenvolvendo novos conhecimentos, independente de ter um tutor demonstrando os passos e os caminhos de um processo (NOGUEIRA, 2009, p.45-47). 
Figura 1. Trecho da coluna do editorial do jornal escolar da ciência. edição de maio.

\section{JORNAL ESCOLAR DA CIÊNCIA}

PUBLICAÇÁO DA ESCOLA ESTADUAL MARINETE DE SOUZA LIRA - SERRA - ESPÍRITO SANTO, 03 DE MAIO DE 2012 - ANO I - No. 01, ISSN 1111-1111

\section{Editorial}

No jornal deste mês, teremos em destaque o desenvolvimento agrícola sustentável, que vem valorizando o trabalho de agricultores do estado do Espírito Santo, além de ajudar a manter várias famílias, por meio da sustentabilidade. Na coluna "História da Ciência", vamos falar sobre o cientista alemão Heinrich Rudolf Hertz, descobridor das ondas eletromagnéticas, e toda a sua biografia. Na coluna "Ciência no Mundo", mostraremos a importância da água potável, além dos custos e da forma de obtê-la tem grandes chances de enfraquecer, mas não é possivel entregar toda a iniciativa nas mãos jos EUA. 0 governo brasileiro teme a possibilidade de ausência de países considerados líderes mundiais, mas as expectativas são as melhores possíveis.

\section{Água Potável: Quanto custa e como obtemos? Ciência no Mundo}

Fonte: Dados da pesquisa.

Figura 2. Trecho da coluna do editorial do jornal escolar da ciência. edição de setembro.

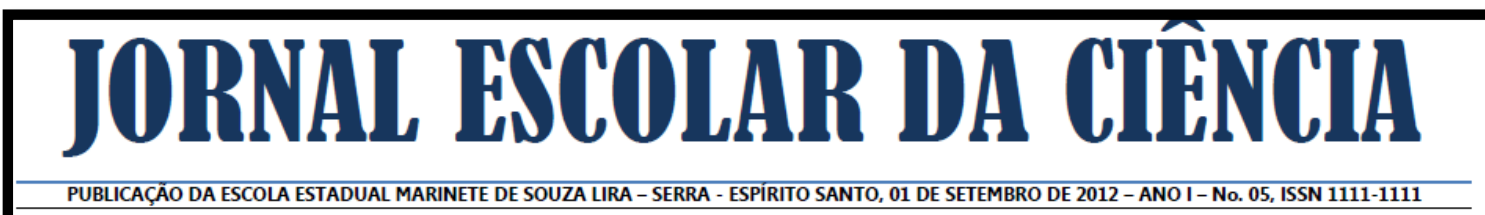

\section{BLOCOS ECONÔMICOS MAIS}

\section{INFLUENTES}

\section{Editorial - Janaína Rosa}

No mundo atual, a globalização é um fator chave que inclui a comercialização, importação e exportação de produtos e principalmente a economia mundial. Em conjunto com a economia vêm os blocos econômicos, entre eles estão as principais potências mundiais como os EUA, Japão, Canadá, Rússia e as potências de menor porte como o Brasil, Paraguai, Colômbia e México. Atualmente os principais blocos econômicos do mundo são a UE (União Europeia), a APEC (Associação de Cooperação Econômica da Ásia e do Pacífico) e o MERCOSUL (Mercado Comum do Sul). O MERCOSUL foi fundado em 1991. constituído por Brasil Paraguai.
Em 1900 já ultrapassava 24 milhões de toneladas (30\% das exportações).

Café: o café se tornou o principal produto da exportação do Brasil, superando o açúcar. O café mudou o país, inclusive incentivando um processo de industrialização com a base em bens de consumo não duráveis. A cafeicultura estimulou toda a economia proporcionando a construção de ferrovias, estradas e portos.

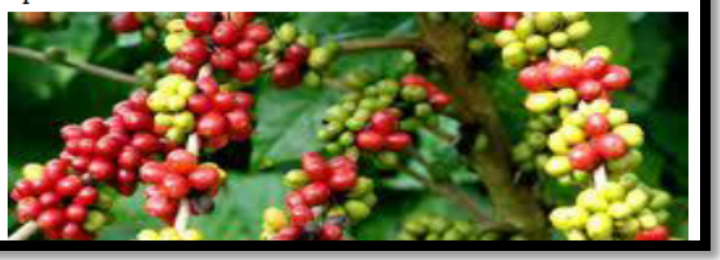

Fonte: Dados da pesquisa. 
Uma das formas de compreender a articulação entre os saberes científicos e saberes escolares e produzindo um diagrama conceitual (articulação conceitos e método de ensino por investigação com enfoque CTSA). Para a construção do diagrama conceitual, utilizamos quatro olhares disciplinares e um olhar interdisciplinar, a saber:

- Políticas públicas, sociologia, filosofia, história e geografia (interdisciplinar).

- ciências biológicas (Biologia).

- ciências químicas (Química).

- ciências físicas (Física).

- matemática (Matemática).

Assim, foi possível verificar o potencial de abordagem de conteúdos conceituais (e outros) a serem tratados durante o processo de construção do jornal escolar da ciência (Figura 3).

Figura 3. Potenciais conteúdos conceituais abordados durante o processo de construção do jornal escolar da ciência com o tema "Alimentos".

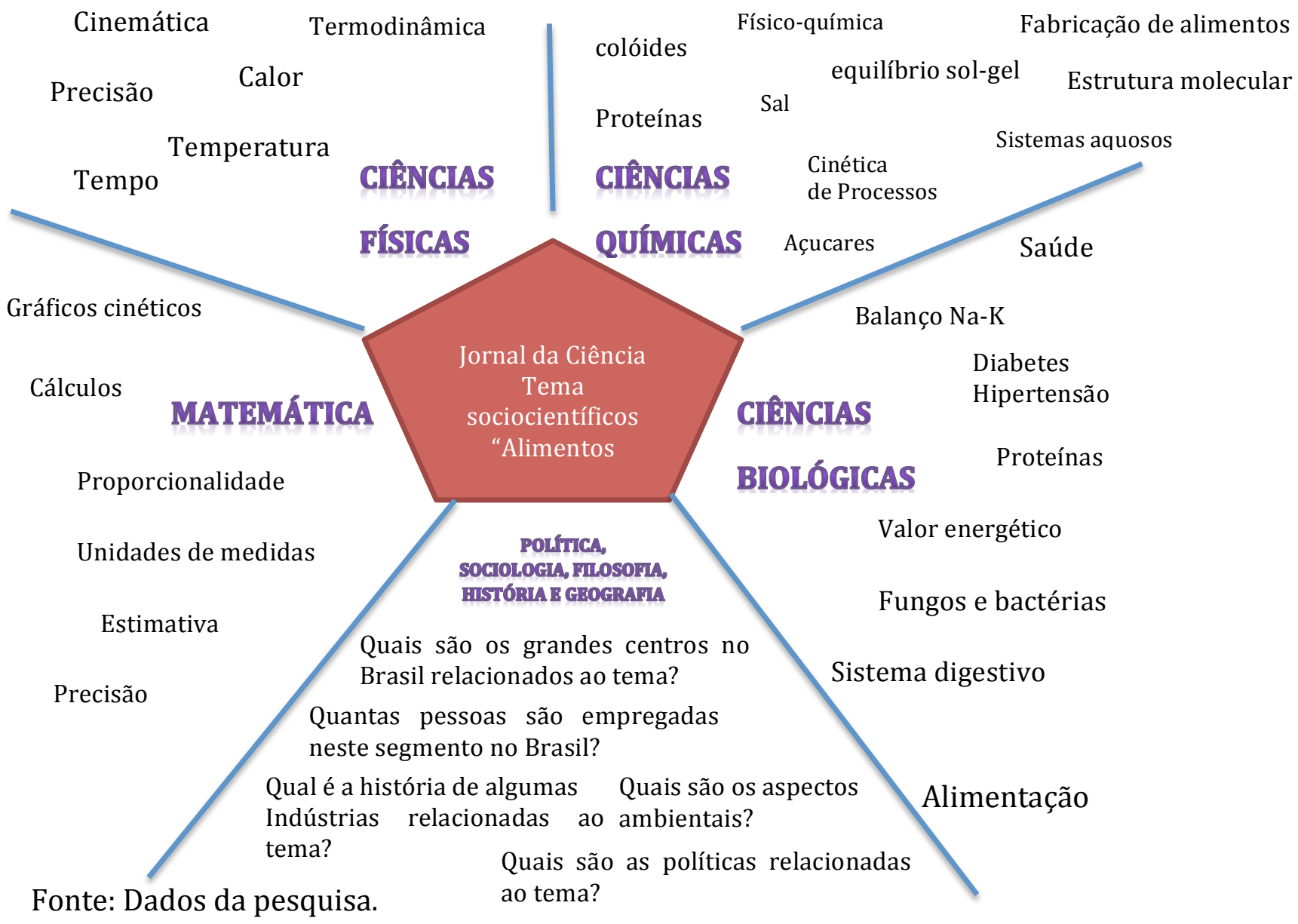


Para Sasseron e Carvalho (2008), há três pontos importantes que determinam o alcance da alfabetização científica, também chamados de eixos estruturantes da Alfabetização Científica, porque servem para balizar a idealização, o planejamento e a análise de propostas de ensino que almejem a AC. 0 Quadro 3 apresenta uma análise dos projetos escolares tendo em vista a AC dos alunos de IC Jr, segundo Sasseron e Carvalho (2008).

0 primeiro eixo estruturante refere-se à compreensão básica de termos, conhecimentos e conceitos científicos fundamentais e a importância deles reside na necessidade exigida em nossa sociedade de se compreender conceitos-chave como forma de poder entender até mesmo pequenas informações e situações do dia-a-dia. 0 segundo eixo refere-se à compreensão da natureza da ciência e dos fatores éticos e políticos que circundam sua prática. Já o terceiro eixo estruturante da AC compreende o entendimento das relações existentes entre ciência, tecnologia, sociedade e meio-ambiente e perpassa pelo reconhecimento de que quase todo fato da vida de alguém tem sido influenciado, de alguma maneira, pelas ciências e tecnologias. Ao realizar os projetos escolares nessa perspectiva, foi possível identificar os três eixos estruturantes, evidenciando o caráter da AC presente nas duas experiências pedagógicas realizadas.

Quadro 3. Análise dos projetos escolares tendo em vista à alfabetização científica dos alunos de IC Jr, segundo Sasseron e Carvalho (2008).

\begin{tabular}{|c|l|}
\hline $\begin{array}{c}\text { Eixos Estruturantes da } \\
\text { Alfabetização Científica }\end{array}$ & \multicolumn{1}{c|}{$\begin{array}{c}\text { Projeto A } \\
\text { Jornal Escolar da Ciência }\end{array}$} \\
\hline $\begin{array}{c}\text { Compreensão básica de termos, } \\
\text { conhecimentos e conceitos } \\
\text { científicos fundamentais }\end{array}$ & $\begin{array}{l}\text { Em todos os temas abordados nos números dos jornais } \\
\text { continham conteúdos fundamentais de ciência. }\end{array}$ \\
\hline $\begin{array}{c}\text { Compreensão da natureza da ciência } \\
\text { e dos fatores éticos e políticos }\end{array}$ & $\begin{array}{l}\text { Temas socioambientais contendo questões do Estado } \\
\text { do Espírito Santo articulou conteúdos científicos com } \\
\text { os aspectos éticos e políticos. }\end{array}$ \\
\hline $\begin{array}{c}\text { Relações existentes entre ciência, } \\
\text { tecnologia, sociedade e meio- } \\
\text { ambiente }\end{array}$ & $\begin{array}{l}\text { A superação da neutralidade da Ciência. A construção } \\
\text { de cada número promoveu uma ciência } \\
\text { inter/multidisciplinar, a partir de situações locais e } \\
\text { regionais, além da ciência tradicional. }\end{array}$ \\
\hline
\end{tabular}




\section{CONSIDERAÇÕES FINAIS}

O projeto escolar foi promoveu a interação dos saberes escolares com os saberes científicos, normalmente contidos nos conteúdos programáticos escolares. A perspectiva inter/multidisciplinar do projeto escolar propiciou a discussão tanto de temáticas disciplinares das ciências exatas, como também das ciências da saúde, sociais e humanas.

Com a realização do projeto escolar, houve a promoção de debates sobre questões da ciência, tecnologia, ambientais e outras questões importantes para cidadania, sobretudo, abordando problemas do locais onde viviam. A construção do jornal da ciência se constituiu em práticas pedagógicas abordando conteúdos conceituais, procedimentais e atitudinais, como por exemplo, os alunos puderam resolver problemas, desenvolver competências e habilidades contribuindo para uma formação integral. De alguma forma, parece ter havido uma contribuição na emancipação política e sociocultural dos alunos de iniciação científica júnior.

O projeto escolar propiciou a alfabetização científica funcional, já que os alunos tiveram que estudar alguns conceitos científicos, inclusive articulando com os conteúdos estudados em sala de aula. Também, propiciou a alfabetização cultural, já que os alunos tiveram que estudar algumas leis, as questões da ética e valores humanos, tiveram que debates assuntos e se posicionarem frente algumas questões polêmicas e controversas, principalmente aquelas relativas à ciência, tecnologia e ambiente. Finalmente, o projeto escolar foi importante para discutir as relações entre ciência, tecnologia, sociedade e ambiente, sobretudo quando se buscou compreender os aspectos históricos e socioeconômicos relacionados à alguns temas abordados nos jornais.

O crescimento dos jovens durante o projeto foi perceptível. Os manifestos realizados por eles durante o projeto, demonstravam a mudança conceitual, procedimental e atitudinal se efetivarem nos alunos de IC Jr. Esse fato ficou claro quando os alunos apresentaram o seminário de IC Jr., na Fapes no fim do ano de 2012. Um dos resultados marcantes, uma das alunas de IC Júnior passou no vestibular da Universidade Federal. Esses resultados apontaram para uma inclusão do movimento CTSA nas escolas públicas por meio de projetos escolares. Entendemos ainda que houve uma contribuição para a formação de cidadania, de autonomia, a partir da formulação de uma opinião crítica e do desenvolvimento do indivíduo para 
participar ativamente na sociedade democrática, na busca de solução de problemas que envolvam aspectos tecnológicos, sociais, econômicos e políticos.

\section{AGRADECIMENTOS}

Agradecemos à Fundação de Amparo à Pesquisa do Estado do Espírito Santo e ao CNPq por apoio financeiro concedido. Aos alunos do ensino médio que atuaram como IC Jr., a aluno de graduação que atual como bolsista de IC e a coordenação pedagógica da escola.

\section{REFERÊNCIAS}

AIKENHEAD, Glen S. Educação Científica para todos. Tradução de Maria Teresa Oliveira. 1ª. Edição. Mangualde - PT: Edições Pedagogo. 2009.

BARDIN, Laurence. Análise de conteúdo, 3ạ. Edição, Lisboa: Edições 70, 2004.

BONINI, Adair; Jornal escolar: gêneros e letramento midiático no ensino-aprendizagem de linguagem. RBLA, Belo Horizonte, v. 11, n. 1, p. 149-175, 2011.

CACHAPUZ, A. Gil-Perez, D. Carvalho, A. M. P. de. Praia, J. Vilches, A. (2005). A necessária renovação do ensino das ciências. São Paulo: Cortez.

CORDIOLLI, Marcos. Os projetos como forma de gestão do trabalho pedagógico em sala de aula. Curitiba: A Casa de Astérion, 2006.

DELIZOICOV, Demétrio; ANGOTTI, José André; PERNANBUCO, Marta Maria. Ensino de ciências: fundamentos e métodos. 4aㅡ Ed. São Paulo: Cortez, 2011.

GATTI, B. A. (2010). Formação de Professores no Brasil: características e problemas. Educação e Sociedade, Campinas, 31(113), 1355 -1379, Out.-Dez.

HÉRNANDEZ, Fernando; VENTURA, Montserrat. A organização do currículo por projetos de trabalho. Trad. Jussara Haubert Rodrigues. 5.ed. Porto Alegre: Artmed, 2007.

LEITE, S. Q. M. L. (2012). Práticas Experimentais Investigativas em Ensino de Ciências. Vitória: Editora IFES.

LÜDKE, M. ANDRÉ, M. E. D. A. (1986). Pesquisa em educação: abordagens qualitativas. São Paulo: EPU.

MARCONI, Marina de Andrade.; LAKATOS, Eva Maria; Metodologia do Trabalho Científico, 7ª. Edição Revista e Ampliada, São Paulo:Editora Atlas, 2009. 
NOGUEIRA, Nilbo Ribeiro. Pedagogia dos projetos: etapas, papéis e atores. São Paulo: Érica, 2005.

OCDE (2006). Evolution of student interest in science and technology studies. Organization for Economic Co-operation and Development - Global Science Forum Policy Report, may.

SANTOS, Wildson Luis Pereira dos; AULER, D. (Org.). CTS e educação científica. Desafios, tendências e resultados de pesquisa. Brasília: Editora UnB. 2011.

TENREIRO-VIEIRA, C.; VIEIRA, Rui Marques. Literacia e pensamento crítico: um referencial para a educação em ciências e em matemática. Revista Brasileira de Educação. v. 18 n. 52 jan.mar. 2013.

UNESCO. A ciência para o século XXI: Uma nova visão e uma base de ação. Versão em língua portuguesa. Brasília: Unesco Brasil. 68. 2003.

WAISELFISZ, Julio. Jacobo. 0 ensino das Ciências no Brasil e o PISA. São Paulo: Sangari Brasil, 2009. 